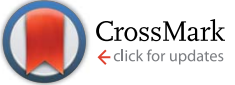

Cite this: RSC Adv., 2017, 7, 2919
Received 18th October 2016 Accepted 19th December 2016

DOI: $10.1039 / c 6 r a 25407 a$

www.rsc.org/advances

\section{A cobalt tungstate compound sensing electrode for hydrogen detection based upon mixed-potential type sensors}

\author{
Y. Li, X. Li, * J. Wang, Y. Jun and Z. Tang \\ An yttria-stabilized cubic zirconia (YSZ) based mixed-potential sensor coupled with $\mathrm{CoWO}_{4}$ as the sensing \\ electrode was developed for hydrogen detection at elevated temperatures. The developed $\mathrm{CoWO}_{4} / \mathrm{YSZ} / \mathrm{Pt}$ \\ sensor was found to have a good sensitivity to different concentrations of hydrogen from $80 \mathrm{ppm}$ to \\ $960 \mathrm{ppm}$ in a background of $10 \% \mathrm{O}_{2} / \mathrm{N}_{2}$ at $450{ }^{\circ} \mathrm{C}$. The sensor showed excellent selectivity to several \\ possible interferents such as $\mathrm{CO}, \mathrm{C}_{3} \mathrm{H}_{8}$ and $\mathrm{NO}_{2}$. The reproducibility and signal repeatability of the \\ sensor was examined to test the reliability of the sensor. The influence of oxygen variation and humidity \\ in the background on the sensor response was also studied.
}

\section{Introduction}

A reliable hydrogen sensor is highly needed for both process control of a hydrogen based energy system and safety monitoring. ${ }^{1}$ Hydrogen has been explored for hydrogen fuel cells that have been used for stationary electricity generation or proposed for zero-emission combustion engines for automotive electric vehicles. ${ }^{2}$ However, leakage of hydrogen will become dangerous once the concentration is above $4 \%$ when mixed with air. ${ }^{3-5}$ Among the several types of chemical hydrogen sensors reported in the literature, solid-state yttria-stabilized cubic zirconia (YSZ) electrolyte based mixed-potential type sensors show promise to be explored for hydrogen detection in terms of its resistance to harsh corrosive and high temperature environments. ${ }^{\mathbf{4 - 1 0}}$

The working principle of the mixed-potential type gas sensors is based upon the different kinetic electrochemical redox reaction rates of the targeted gas species such as hydrogen with the co-adsorbed oxygen at each interface of electrode/electrolyte. The mixed-potential at each electrode would be generated due to the electrochemically reactions of the gas species with the co-adsorbed oxygen at the gas-electrode-electrolyte also called as the triple-phase-boundary (TPB). By employing different electrode materials, the mixed-potential at each electrode would become different due to the different electrochemical catalytic oxidation ability of each electrode material. The electrical potential difference $(V)$ across the electrochemical cell would be thus collected as the sensor response. ${ }^{11-15}$ This type of sensor has been widely explored for detecting various types of environmental pollutant gases such as $\mathrm{CO}, \mathrm{NO}_{x}(x=1,2)$, hydrocarbons and hydrogen. In particular

School of Electronic Science and Technology, Institute for Sensing Technologies, Key Lab. of Liaoning for Integrated Circuits Technology, Dalian University of Technology, Dalian 116024, China.E-mail: lixg@dlut.edu.cn for the hydrogen sensors, recent work has focused on searching for an appropriate sensing electrode for selectively sensing to hydrogen within a wider concentration range from hundreds of ppm up to 4 vol\%. ${ }^{16-20}$

Metal tungstates with the general formula $\mathrm{MWO}_{4}(\mathrm{M}$ denotes $\mathrm{Zn}, \mathrm{Mn}, \mathrm{Co}, \mathrm{Ni}, \mathrm{Fe}$ etc.) belong to an important family of inorganic functional materials ${ }^{2}$ and their crystal structures are controlled by cationic radii. ${ }^{3}$ These metal tungstates have found potential applications for microwave, photoluminescence devices, and humidity sensors. ${ }^{4,5}$ Some of them have recently been explored for chemical gas sensing applications. It has been reported previously that $\mathrm{MWO}_{4}(\mathrm{M}=\mathrm{Zn}, \mathrm{Mn}, \mathrm{Cd})$ when coupled as the sensing electrodes of the mixed-potential type sensors demonstrated high sensitivity and selectivity to hydrogen. ${ }^{21-23}$ It points out that the sensing electrode using the transitional metals with partly-empty outermost d shell such as $\mathrm{Ni}, \mathrm{Co}$, and $\mathrm{Cr}$ in $\mathrm{MWO}_{4}$ could have better sensitivity and selectivity to lower concentrations of hydrogen.

Cobalt tungstates $\left(\mathrm{CoWO}_{4}\right)$ has been used for antiknock and pigment additives. ${ }^{24,25}$ Recently, it has been explored for a new oxygen carrier material for syngas production because of its attractive catalytic activity and good alternative sensing performance for detection of ammonia. ${ }^{26-28}$ Therefore, in this work, we studied $\mathrm{CoWO}_{4}$ sensing electrode for mixed-potential type hydrogen sensors. The $\mathrm{CoWO}_{4}$ sensing electrode indicated excellent sensitivity and selectivity to hydrogen at even lower temperature of $450{ }^{\circ} \mathrm{C}$ compared to $\mathrm{Zn} / \mathrm{Mn} / \mathrm{CdWO}_{4}$ ones.

\section{Experimental}

\subsection{Materials preparation and characterization}

The $\mathrm{CoWO}_{4}$ powders were prepared by using a hydrothermal method. During the synthesis, $2.64 \mathrm{~g} \mathrm{Na}_{2} \mathrm{WO}_{4} \cdot 2 \mathrm{H}_{2} \mathrm{O}$ (Sinopharm Chemical Reagent Co., Ltd, China) and $1.904 \mathrm{~g}$ 
$\mathrm{CoCl}_{2} \cdot 6 \mathrm{H}_{2} \mathrm{O}$ (Tianjin Kermiou Chemical Reagent Co., Ltd, China) were separately put into two beakers followed with addition of $40 \mathrm{ml}$ deionized water into these two beakers respectively. The two mixtures were magnetically stirred to obtain the two corresponding homogeneous solutions. After that, obtained $\mathrm{Na}_{2} \mathrm{WO}_{4}$ aqueous solution was added into the $\mathrm{CoCl}_{2}$ solution with strong magnetic stirring for 1 hours and the $\mathrm{pH}$ of the solution was adjusted to 9 by adding sodium hydroxide. Then, the mixed solution was poured into a $100 \mathrm{ml}$ Teflon-lined stainless steel vessel and further subject to a heat treatment at $180{ }^{\circ} \mathrm{C}$ for $12 \mathrm{~h}$. The light black precipitates were obtained and washed with deionized water and ethanol for several times, then dried at $80{ }^{\circ} \mathrm{C}$ overnight. Finally, the asprepared products were calcined at $700{ }^{\circ} \mathrm{C}$ for 2 hours and then grinded thoroughly to achieve the final $\mathrm{CoWO}_{4}$ powders.

The crystal structure of the obtained $\mathrm{CoWO}_{4}$ was determined by XRD (XRD-6000, Shimadzu Corp., Japan). The XRD patterns were collected using Ni-filtered $\mathrm{Cu} \mathrm{K} \alpha$ radiation at $40 \mathrm{kV}$ and 25 $\mathrm{mA}$ between $2 \theta$ of $10-60^{\circ}$ at a scanning speed of $12^{\circ} \mathrm{min}^{-1}$. The surface morphology of the sample was analyzed using the scanning electron microscope (SEM, FEI, USA). X-ray photoelectron spectroscopy (XPS) was also analyzed (Thermo escalab 250Xi, Thermo Electron Corp., USA).

\subsection{Sensor fabrication and sensing measurements}

The eight molar percentage yttria-stabilized cubic zirconia ( $8 \%$ YSZ) solid electrolyte disks with a dimension of $10 \times 10 \times 0.2$ $\mathrm{mm}$ were purchased from Shanghai Institute of Ceramics, China. The two opposite surfaces of the $8 \%$ YSZ disk were ultrasonically cleaned with water and acetone several times to remove the dusts and grease. $\mathrm{CoWO}_{4}$ paste was made by mixing as-synthesized $\mathrm{CoWO}_{4}$ powders with the commercial $\alpha$ terpineol (99\%, Shanghai Baoman Biotechnology Co., Ltd., China). Pt paste was similarly made by mixing the commercial Pt powders (mean particle size $100 \mathrm{~nm}$, Kunming Youyan, China) with the $\alpha$-terpineol.

The sensor was then fabricated following the similar procedures. ${ }^{29}$ The structures of the $\mathrm{CoWO}_{4} / \mathrm{YSZ} / \mathrm{Pt}$ sensor is illustrated in Fig. 1. The procedures for fabricating the sensor were involved with the following steps: the Pt pastes were painted on both sides of the YSZ electrolyte plate. Then, the painted Pt pastes were firstly fired at $150{ }^{\circ} \mathrm{C}$ for $2 \mathrm{~h}$ and then $1000^{\circ} \mathrm{C}$ for $2 \mathrm{~h}$ to sinter the $\mathrm{Pt}$ and increase the adhesion of the $\mathrm{Pt}$ to the electrolyte. One face of the Pt thick film would work as the

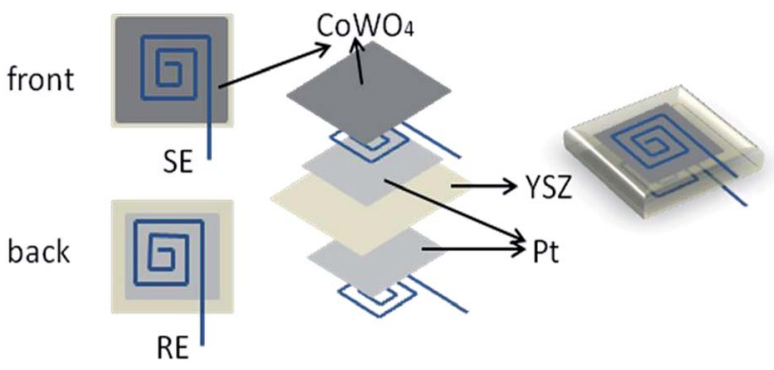

Fig. 1 The structures of the fabricated $\mathrm{CoWO}_{4} / \mathrm{YSZ} / \mathrm{Pt}$ sensor. reference electrode (RE). The other face of the Pt thick film would serve as the current collector. The $\mathrm{CoWO}_{4}$ paste was painted on the top of the current collector and fired at $700{ }^{\circ} \mathrm{C}$ for 2 hours to burn away the organic binders and increase the adhesions of the sensing elements with the electrolyte. The face of the sensor with $\mathrm{CoWO}_{4}$ would work as the sensing electrode (SE).

During the sensor measurements, the as-fabricated planar sensors $\left(\mathrm{CoWO}_{4} / \mathrm{YSZ} / \mathrm{Pt}\right)$ were exposed to the testing gases. The testing gas samples were made by diluting the parent commercial gases such as $\mathrm{H}_{2}, \mathrm{CO}, \mathrm{C}_{3} \mathrm{H}_{8}$ and $\mathrm{NO}_{2}$ each with a concentration of $1500 \mathrm{ppm}$ balanced by nitrogen. The gas flow rate was controlled independently using computer controlled, pre-calibrated electronic mass flow controllers (D07-19B, Beijing Senvenstar Elec-tronics, China). The total gas flow rate was

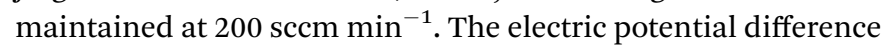
$(\mathrm{V})$ of the sensor was measured by a computer controlled Agilent high impedance digital electrometer (100M, Agilent 34401A). The response of the sensor $\left(R_{\mathrm{s}}, \mathrm{mV}\right)$ was defined as:

$$
R_{\mathrm{s}}=V_{\mathrm{a}}-V_{\mathrm{b}}
$$

where $V_{\mathrm{a}}$ and $V_{\mathrm{b}}$ are the electric potential difference (EPD) of the sensor in the analytes and the background gas $\left(10 \% \mathrm{O}_{2} / \mathrm{N}_{2}\right)$, respectively.

The dc polarization curves of the sensors were measured using the three-electrode configuration. ${ }^{23}$ The three-electrode configuration designed using Pt as the counter electrode (CE) and reference electrode respectively. A variation of dc voltages from 0 to $200 \mathrm{mV}$ at a step of $10 \mathrm{mV}$ was applied across the $\mathrm{CoWO}_{4}$ and counter electrode, the current was measured simultaneously by a Keithley system source meter ( 1 pA to $10 \mathrm{~A}$, Keithley 2612).

\section{Results and discussion}

\subsection{Preparation and characterizations of $\mathrm{CoWO}_{4}$}

Fig. 2(a) shows the XRD pattern of the prepared $\mathrm{CoWO}_{4}$ powders. The XRD peaks were indexed according to JCPDS No. 72-0479. The crystal structure consists of a single monoclinic phase. Fig. 2(b) shows the surface morphology of calcined $\mathrm{CoWO}_{4}$ powders at $700{ }^{\circ} \mathrm{C}$. The particles in the sample indicated a rod-like morphology with a length $\sim 300-500 \mathrm{~nm}$ and a diameter of the cross section $\sim 100-200 \mathrm{~nm}$.

Fig. 3 shows the XPS spectra of the synthesized $\mathrm{CoWO}_{4}$ powders. Fig. 3(a) shows the survey of the XPS of the sample. It shows that the existence of the three elements such as Co, $\mathrm{W}$ and $\mathrm{O}$ in the composite. Fig. 3(b) is the local XPS region of Co2p. The coupled two peaks at $780.1 \mathrm{eV}$ and $795.5 \mathrm{eV}$, respectively, have $\Delta E=15.4 \mathrm{eV}$ indicating that the Co has a valence of $+3 .^{30}$ The O1s peak at $529.6 \mathrm{eV}$ shown in Fig. 3(c) corresponds to the lattice oxygen. However, the two peaks of W4f centered at $34.5 \mathrm{eV}$ and $36.7 \mathrm{eV}$ shown in Fig. 3(d) indicates that the $\mathrm{W}$ has a valence of +6 in the compound. ${ }^{31}$ Therefore, the formula of the compound should be more precisely noted as $\mathrm{CoWO}_{4.5}$ with excess oxygen. The excess incorporation of oxygen in the 

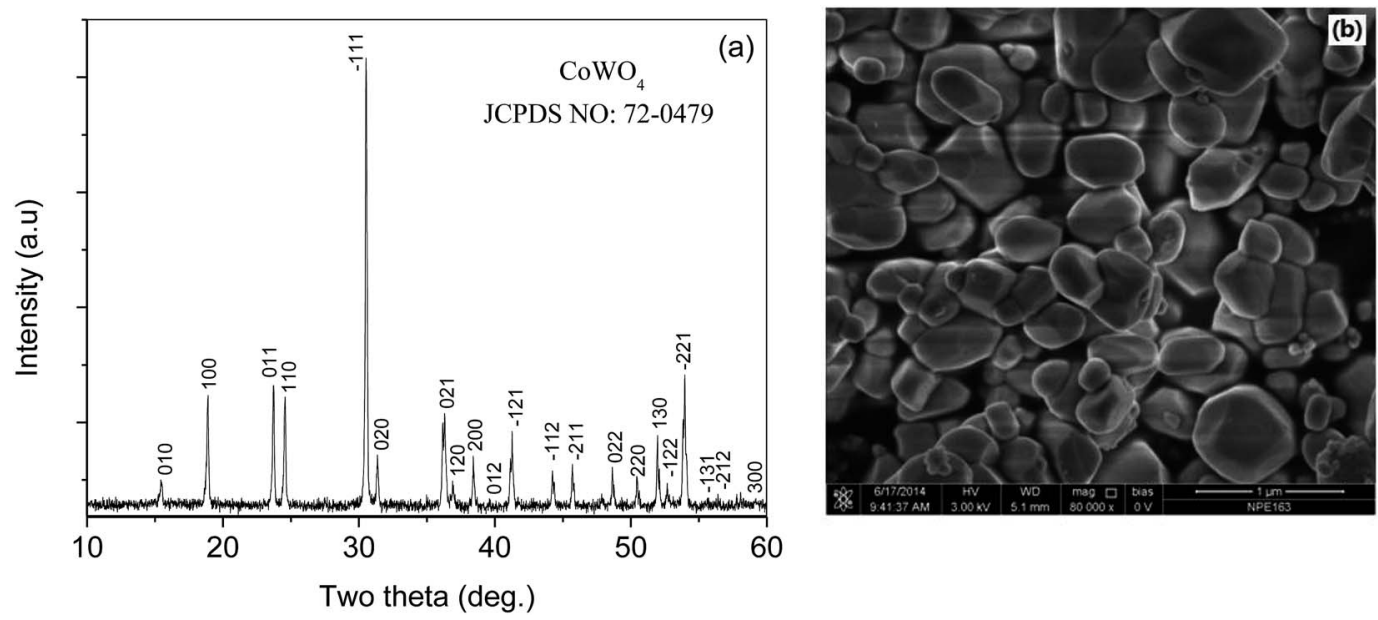

Two theta (deg.)

Fig. 2 (a) XRD pattern (b) SEM image of $\mathrm{COWO}_{4}$ calcined at $700{ }^{\circ} \mathrm{C}$.

compound could be caused by the calcination of the sample at high temperature in air.

\subsection{Sensing properties}

Fig. 4(a) shows the response curves of the $\mathrm{CoWO}_{4} / \mathrm{YSZ} / \mathrm{Pt}$ sensor to different concentrations of hydrogen from $80 \mathrm{ppm}$ to $960 \mathrm{ppm}$ in $10 \% \mathrm{O}_{2} / \mathrm{N}_{2}$ at $400{ }^{\circ} \mathrm{C}, 450{ }^{\circ} \mathrm{C}$ and $500{ }^{\circ} \mathrm{C}$. As the temperature increased from $400{ }^{\circ} \mathrm{C}$ to $500{ }^{\circ} \mathrm{C}$, the sensor has the highest response at $450{ }^{\circ} \mathrm{C}$ than the other two temperatures and thus the optimum operating temperature of the sensor is $450{ }^{\circ} \mathrm{C}$.

Fig. 4(b) shows the calibration curve of the sensor to different concentrations of hydrogen. An approximately logarithmic relationship between the open-circuit electrical potential difference and the concentrations of hydrogen from $80 \mathrm{ppm}$ to $960 \mathrm{ppm}$ was observed indicating that the polarization of the sensor should be within the Tafel-region. Among the three
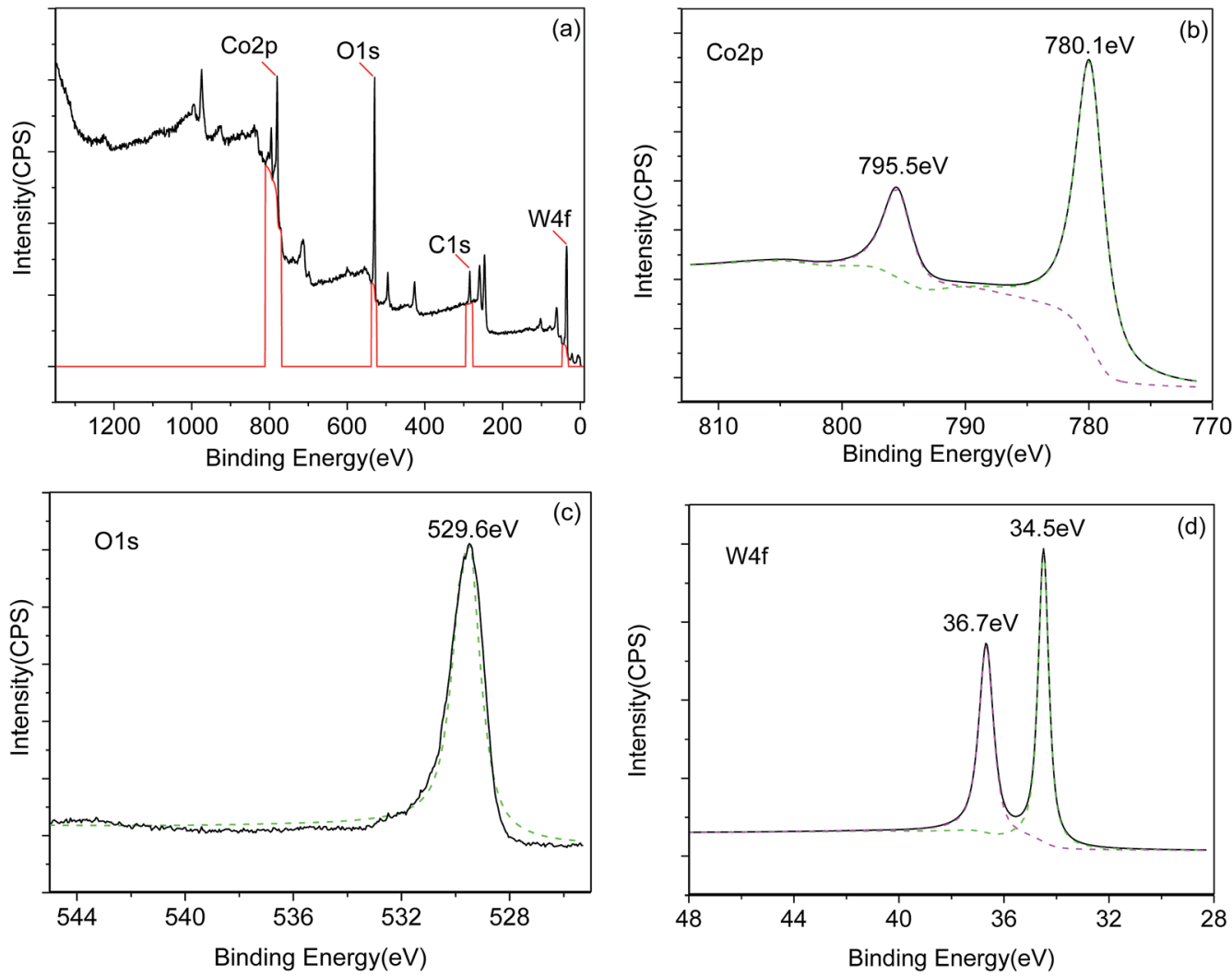

Fig. 3 XPS spectra of as-synthesized $\mathrm{CoWO}_{4}$ powers (a) survey (b) Co2p (c) O1s and (d) W4f. 

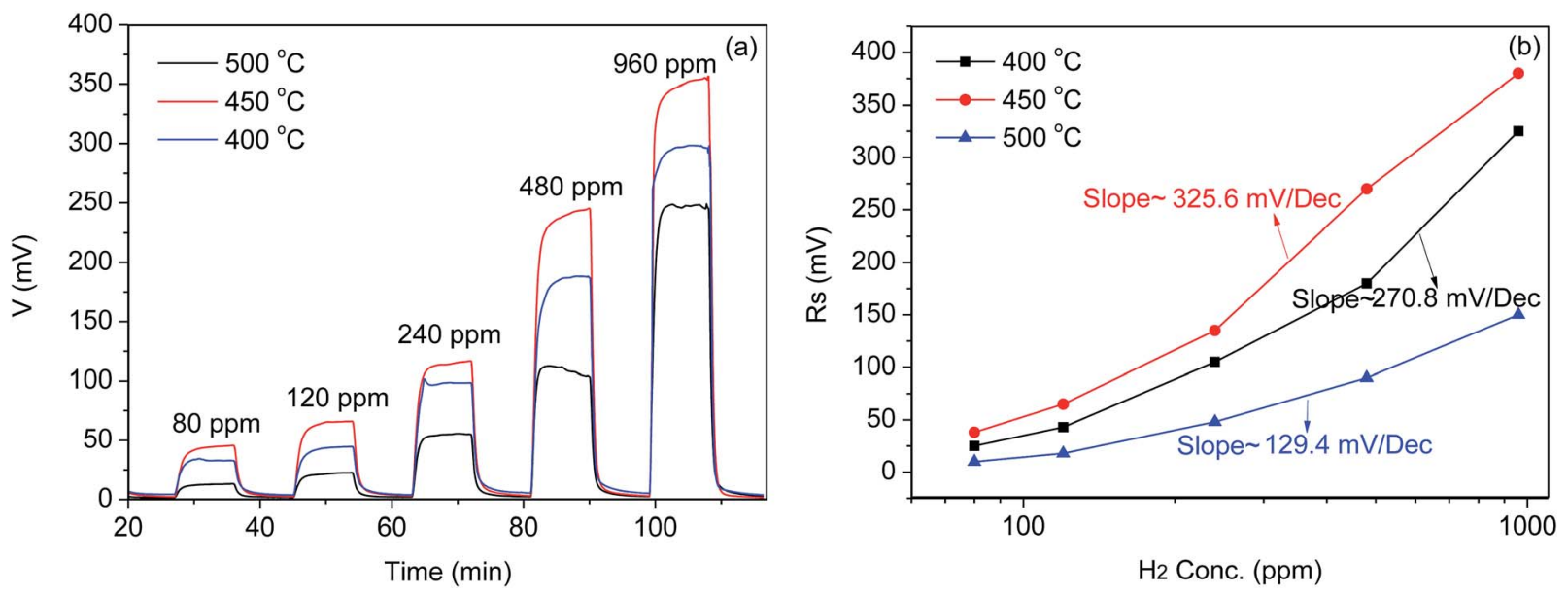

Fig. 4 (a) Response curve (b) calibration curves of the CoWO $4 / Y S Z / P t$ sensor to different concentrations of hydrogen from 80 ppm to 960 ppm within the temperature range from $400{ }^{\circ} \mathrm{C}$ to $500^{\circ} \mathrm{C}$.

temperatures of $400{ }^{\circ} \mathrm{C}, 450{ }^{\circ} \mathrm{C}$ and $500{ }^{\circ} \mathrm{C}$, the calibration curves has the largest slope of $325.6 \mathrm{mV} \mathrm{dec}{ }^{-1}$ at $450{ }^{\circ} \mathrm{C}$ indicating the best sensitivity. The sensing properties of the $\mathrm{CoWO}_{4} /$ YSZ/Pt sensor to different concentrations of hydrogen could be explained by the mixed potential theory. ${ }^{4-23}$ The sensor response, i.e. the electrical potential difference (EPD) across the two electrodes, is dependent upon the electrochemical redox reactions occurring at each TPB of the electrochemical cell according to:

$$
\begin{gathered}
\mathrm{O}_{2} \text { (adsorbed) }+4 \mathrm{e}^{-} \rightarrow 2 \mathrm{O}^{2-}(\mathrm{YSZ}) \\
2 \mathrm{H}_{2} \text { (co-adsorbed) }+2 \mathrm{O}^{2-}(\mathrm{YSZ}) \rightarrow 2 \mathrm{H}_{2} \mathrm{O}+4 \mathrm{e}^{-}
\end{gathered}
$$

Since the $\mathrm{CoWO}_{4}$ oxide and Pt electrodes have a different ability to electrochemically convert hydrogen to water vapor, the degree of the electrochemical reactions ((2) and (3)) at each ТРВ became different. Thus, the generated mixed-potential at each electrode (TPB) would be different consequently leading to the observed response. The optimum working temperature was found at $450{ }^{\circ} \mathrm{C}$ in terms of response and sensitivity as shown in Fig. 4. At lower temperatures such as $400{ }^{\circ} \mathrm{C}$ or below, the ionic conductivity of the YSZ electrolyte would become lower and the sensor response became smaller. One more reason for the lower response at $400{ }^{\circ} \mathrm{C}$ may lie in that the electrochemical catalytic properties of $\mathrm{CoWO}_{4} / \mathrm{YSZ}$ interface became weak leading to the less reactions of hydrogen with the adsorbed oxygen according to reaction (3). As the operated temperature increased to $500{ }^{\circ} \mathrm{C}$, the non-electrochemically catalytic conversion of hydrogen by the both electrodes would become more and more dominant. The difference of oxygen concentrations at TPB of each electrode diminished resulting to the lower response observed at $500{ }^{\circ} \mathrm{C}$.

To further confirm that the $\mathrm{CoWO}_{4} / \mathrm{YSZ} / \mathrm{Pt}$ sensor worked in accordance with the mixed-potential theory, the dc polarization curves of the sensor in air and in different concentrations of hydrogen at $120 \mathrm{ppm}$ and $240 \mathrm{ppm}$ were measured as shown in Fig. 5.

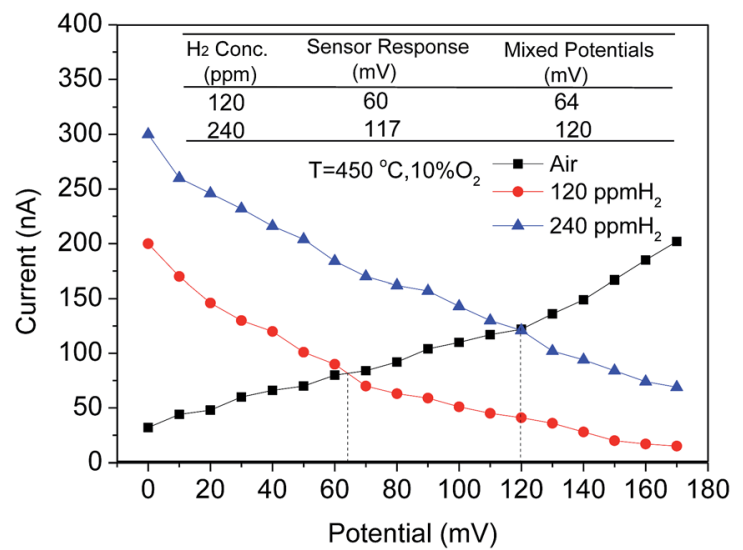

Fig. 5 Polarization curves of the sensors in $10 \% \quad \mathrm{O}_{2} / \mathrm{N}_{2}$ and in hydrogen environment at $450^{\circ} \mathrm{C}$.

The values at the cross point of the polarization curves of the sensor in air and in different concentrations of hydrogen were estimated for the sensor responses, the electrical potential difference between the mixed-potentials generated at each electrode $\left(\mathrm{CoWO}_{4}\right.$ and $\left.\mathrm{Pt}\right)$ due to the different electrochemically redox reaction rates of hydrogen with adsorbed oxygen at each TPB.

A comparison of the estimated response from the polarization curves and the measured values is summarized in the inset table in Fig. 5. These two values are approximately close to each other indicating that the sensor works based on the mixedpotential mechanism.

The sensitivity of the sensor to some possible interferents such as $\mathrm{CO}, \mathrm{C}_{3} \mathrm{H}_{8}$ and $\mathrm{NO}_{2}$ were measured. Fig. 6 shows the response of the sensor to different concentrations of $\mathrm{CO}, \mathrm{C}_{3} \mathrm{H}_{8}$ and $\mathrm{NO}_{2}$ from $80 \mathrm{ppm}$ to $960 \mathrm{ppm}$ in the background of $10 \mathrm{vol} \%$ $\mathrm{O}_{2} / \mathrm{N}_{2}$ at $450{ }^{\circ} \mathrm{C}$.

The slope of the calibration curve of the sensor to $\mathrm{H}_{2}$ is around $57.69 \mathrm{mV} \mathrm{dec}^{-1}$ which is much larger than those three other gases. Therefore, the sensor indicates a higher sensitivity 


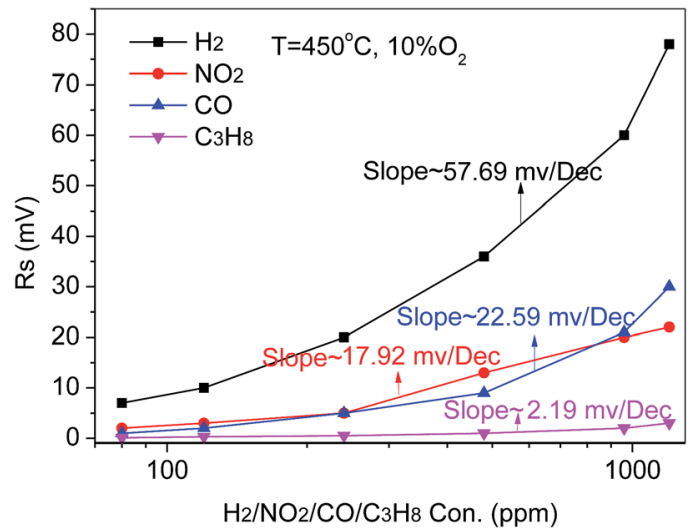

Fig. 6 Comparison of the response of the $\mathrm{CoWO}_{4} / \mathrm{YSZ} / \mathrm{Pt}$ sensor to the interferents $\mathrm{C}_{3} \mathrm{H}_{8} / \mathrm{NO}_{2} / \mathrm{CO}$ at lower concentrations than $1500 \mathrm{ppm}$ at $450{ }^{\circ} \mathrm{C}$.

to $\mathrm{H}_{2}$ relative to the three possible interferents $\left(\mathrm{CO}, \mathrm{C}_{3} \mathrm{H}_{8}\right.$ and $\mathrm{NO}_{2}$ ) thus indicating possibly good selectivity.

The oxygen influence on the sensor response was also examined as shown in Fig. 7. The response was suppressed in the higher oxygen concentration background. This might be due to the enhanced catalytic reactions of hydrogen with the rich oxygen before hydrogen diffused to the TPB leading to an effective lower hydrogen concentration to participate in the electrochemical reactions according to reaction (3) at TPB and thus the lower response.

Although the response of the sensor is the highest in the background of $5 \mathrm{vol} \% \mathrm{O}_{2} / \mathrm{N}_{2}$, the response times and recovery times of the sensor became much longer. Therefore, the oxygen concentrations in the background need to be controlled at 10 vol\% $\mathrm{O}_{2} / \mathrm{N}_{2}$ during the operation of the sensor.

Fig. 8 shows the repeatability of response of the sensor at $960 \mathrm{ppm} \mathrm{H}_{2}$ in a background of $10 \mathrm{vol} \% \mathrm{O}_{2} / \mathrm{N}_{2}$ at $450{ }^{\circ} \mathrm{C}$. The responses indicated a good repeatability during the several cycling tests. The response time and recovery time is around $145 \mathrm{~s}$ and $120 \mathrm{~s}$, respectively.

The sensor to sensor consistency (i.e. reproducibility) was investigated. Fig. 9(a) and (b) show the response curves of the

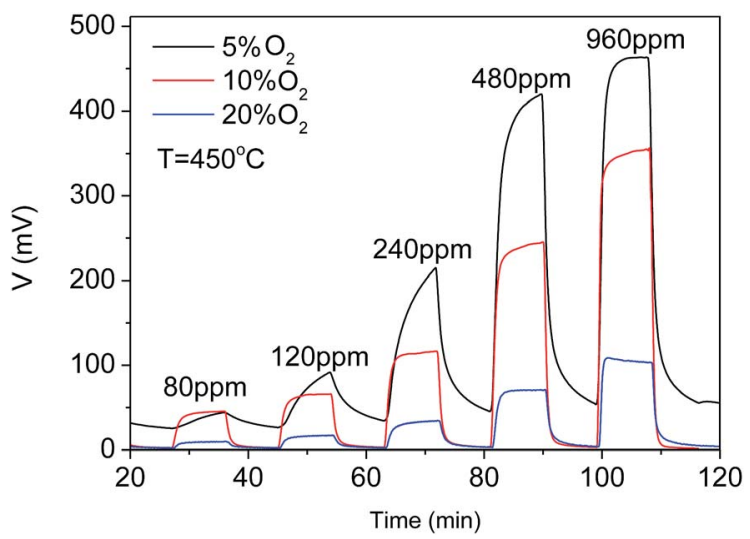

Fig. 7 Influence of oxygen to $\mathrm{CoWO}_{4} / \mathrm{YSZ} / \mathrm{Pt}$ hydrogen sensor at $450{ }^{\circ} \mathrm{C}$ in the background of $5 \mathrm{vol} \%, 10 \mathrm{vol} \%$ and 20 vol\% $\mathrm{O}_{2} / \mathrm{N}_{2}$.

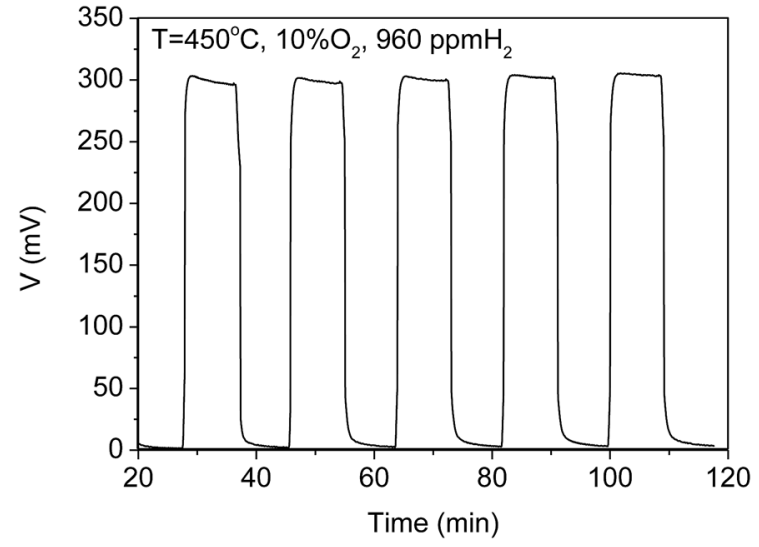

Fig. 8 Repeatability of the response of the $\mathrm{CoWO}_{4} / \mathrm{YSZ} / \mathrm{Pt}$ sensor at $960 \mathrm{ppm} \mathrm{H} \mathrm{H}_{2} 450{ }^{\circ} \mathrm{C}$ in the background of $10 \mathrm{vol} \% \mathrm{O}_{2} / \mathrm{N}_{2}$.

three sensors and the correlation plots of the sensor response as a function of the $\mathrm{H}_{2}$ concentrations from $80 \mathrm{ppm}$ to $960 \mathrm{ppm}$ at $450{ }^{\circ} \mathrm{C}$ in the background of $10 \mathrm{vol} \% \mathrm{O}_{2} / \mathrm{N}_{2}$, respectively. There is a slight difference in the sensor response to the same
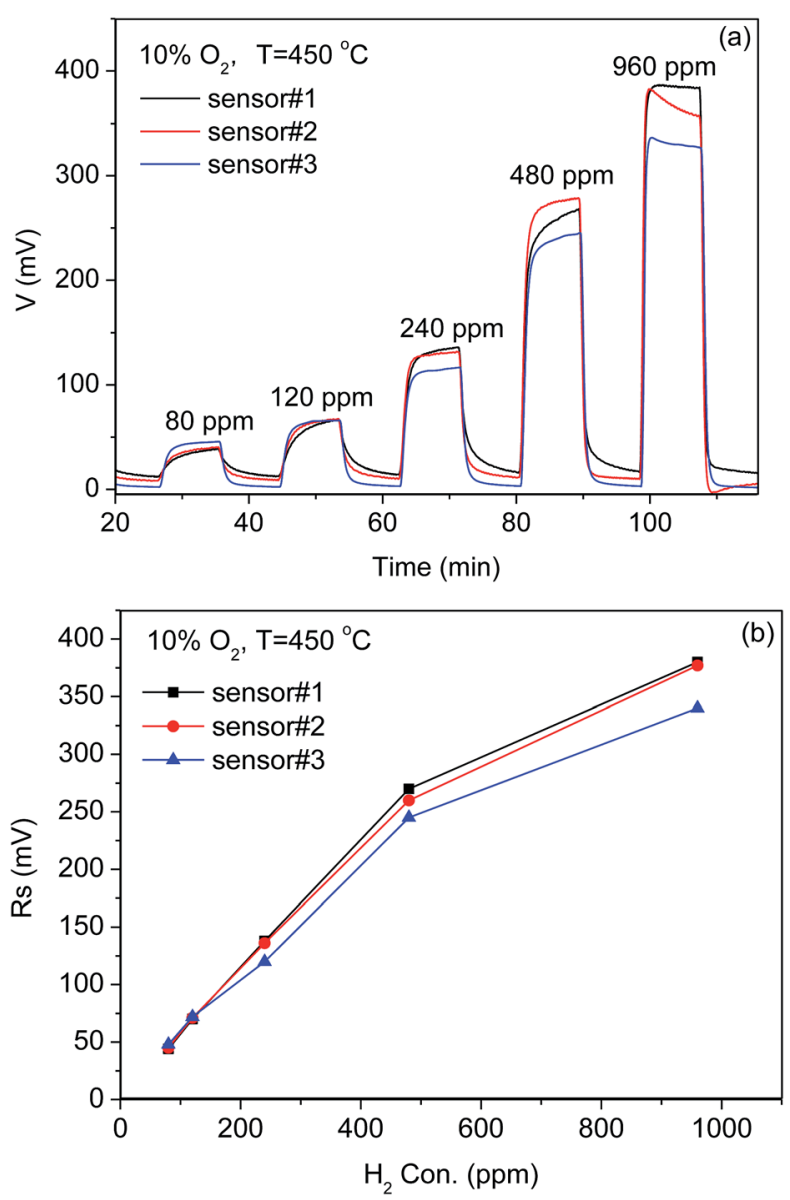

Fig. 9 Reproducibility of three $\mathrm{CoWO}_{4} / \mathrm{YSZ} / \mathrm{Pt}$ sensors to different concentrations of $\mathrm{H}_{2}$ from $80 \mathrm{ppm}$ to $960 \mathrm{ppm}$ at $450{ }^{\circ} \mathrm{C}$ in the background of $10 \mathrm{vol} \% \mathrm{O}_{2} / \mathrm{N}_{2}$ (a) response curve of the sensors with the hydrogen concentrations from 80 ppm to 960 ppm (b) correlation plots. 
concentration of $\mathrm{H}_{2}$. This may be caused by the chemical processes used for fabricating the thick-film electrodes. The $\mathrm{CoWO}_{4}$ and Pt thick film electrodes were manually painted in this work and thus the microstructure may vary from one sensor to another. Therefore, the processes for fabricating the sensors should be carefully controlled to improve the consistency of the sensors during the mass production.

Fig. 10 shows the effect of the humidity on the response of the sensor to different concentrations of hydrogen. The response of the sensor decreased in presence of the $\mathrm{RH} \sim 98 \%$ in the background. This could be understood that the reaction (3) would prefer moving backward and thus the electrochemical oxidation process would be suppressed with the presence of water vapor.

Consequently, the generated mixed potential would decrease at the oxide electrode. Moreover, the response and recovery time became slower compared to that without water vapor which is similar to the results reported previously. ${ }^{21-23}$ This might indicate that the co-adsorbed water molecular with oxygen at the TPB could decrease the reaction rate of reaction (3) as well. The

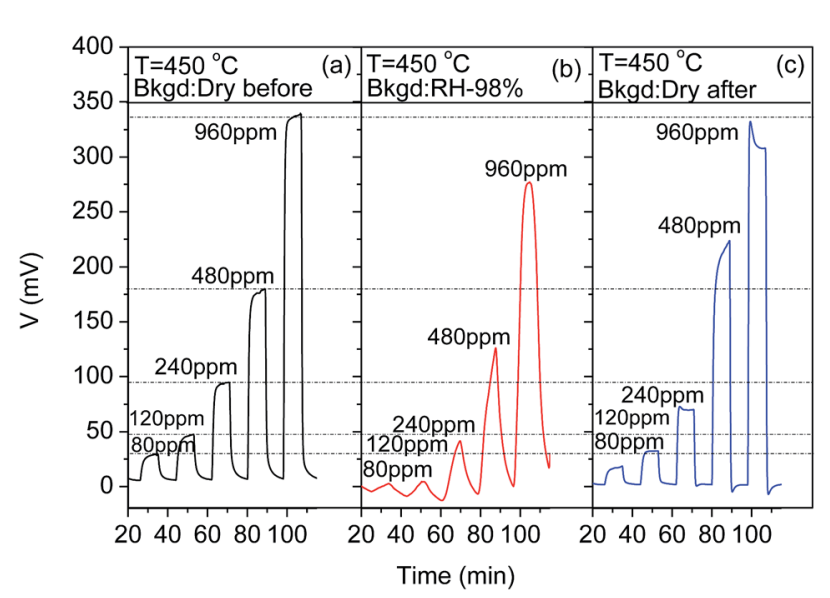

Fig. 10 Influence of the humidity on the response of the $\mathrm{CoWO}_{4} / \mathrm{YSZ}$ I Pt sensor at $450{ }^{\circ} \mathrm{C}$ in the background of 10 vol\% $\mathrm{O}_{2} / \mathrm{N}_{2}$.

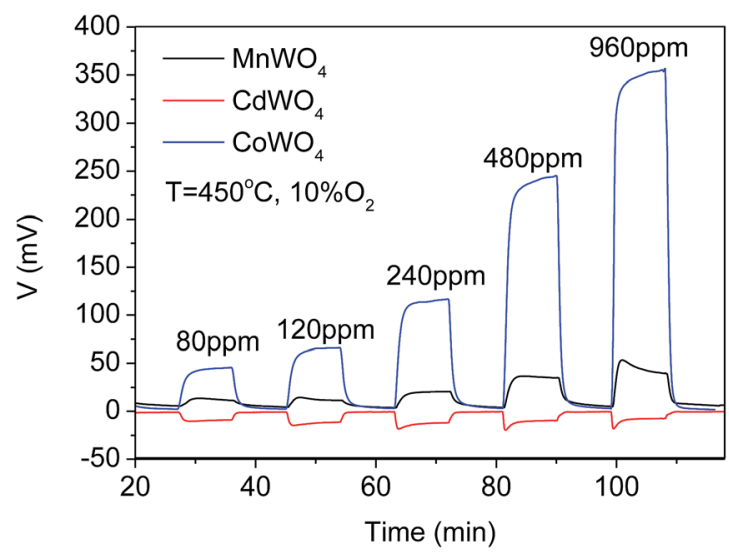

Fig. 11 Comparison of the response of $\mathrm{CoWO}_{4}$ sensing electrode with the sensing electrodes of $\mathrm{MnWO}_{4}$ and $\mathrm{CdWO}_{4}$ to different concentrations of $\mathrm{H}_{2}$ from $80 \mathrm{ppm}$ to $960 \mathrm{ppm}$ in the background of $10 \mathrm{vol} \%$ $\mathrm{O}_{2} / \mathrm{N}_{2}$ at $450{ }^{\circ} \mathrm{C}$. sensor would almost recover after the water vapor was removed from the gas stream as shown in Fig. 10(c).

Compared with the $\mathrm{MnWO}_{4}$ and $\mathrm{CdWO}_{4}$ sensing electrodes reported previously, ${ }^{22,23} \mathrm{CoWO}_{4}$ sensing electrode shows a better sensitivity to the lower concentrations of hydrogen at even lower working temperature of $450{ }^{\circ} \mathrm{C}$ as shown in Fig. 11. Similar to $\mathrm{Cd}^{2+}$ in the $\mathrm{CdWO}_{4}$ sensing electrode, $\mathrm{Co}^{3+}$ has the incomplete occupied outest shell of $\mathrm{d}$ orbital. It has been proposed in literature that the unoccupied d orbital could enhance the chemical adsorption of hydrogen containing species such as hydrogen, hydrocarbons and alcohols on transition metal oxides and thus a possible better catalytic properties to these gas vapors. Therefore, it may be responsible for the better sensitivity of the $\mathrm{CoWO}_{4}$ sensing electrode to lower concentrations hydrogen. ${ }^{23,27}$ The lower operating temperature of $\mathrm{CoWO}_{4}$ compared to $\mathrm{CdWO}_{4}$ and $\mathrm{MnWO}_{4}$ sensing electrodes may be attributed to the existence of the cobalt metal in the compound that has known catalytic conversion ability at low temperatures. ${ }^{32-36}$

The better catalytic properties of $\mathrm{CoWO}_{4}$ could effectively electrochemically oxidation of hydrogen at TPB thus resulting to a better response at the lower temperature. However, further decreasing the operating temperature of the sensor could be limited by the ionic conductivity of the YSZ electrolyte.

\section{Conclusions}

The YSZ-based mixed-potential type sensor using $\mathrm{CoWO}_{4}$ and Pt as the two electrodes exhibited good response to different hydrogen concentrations from $80 \mathrm{ppm}$ to $960 \mathrm{ppm}$ at $450{ }^{\circ} \mathrm{C}$ in the $10 \% \mathrm{O}_{2} / \mathrm{N}_{2}$ background. The sensor also indicates higher sensitivity to $\mathrm{H}_{2}$ compared to $\mathrm{CO}, \mathrm{C}_{3} \mathrm{H}_{8}$ and $\mathrm{NO}_{2}$ and shows good signal repeatability and sensor reproducibility. The lower operating temperature of the $\mathrm{CoWO}_{4}$ sensing electrodes compared to $\mathrm{MnWO}_{4}$ and $\mathrm{CdWO}_{4}$ based ones could be due to the better catalytic properties of $\mathrm{CoWO}_{4}$ to hydrogen at lower temperatures. The sensor response would be likely to be affected by the variation of humidity and oxygen concentrations in the background. However, it could be solved by filtering the gas stream and by keeping the oxygen concentration constant in the testing chamber during the operation of the sensor in real scene.

\section{Acknowledgements}

This study was supported by the National Natural Science Foundation of China (61474012, 61611130065, 61574025, $61274076,61131004)$. The financial support from the Foundation of Key Lab. for Micro/Nano Technology and System of Liaoning Province (Grant No. 20140404) are also acknowledged.

\section{References}

1 M. Yamaguchi, S. A. Anggraini, Y. Fujio, M. Breedon, V. V. Plashnitsa and N. Miura, Electrochim. Acta, 2012, 76, 152-158. 
2 W. J. Buttner, M. B. Post, R. Burgess and C. Rivkin, Int. J. Hydrogen Energy, 2011, 36, 2462-2470.

3 T. Hubert, L. Boon-Brett, G. Black and U. Banach, Sens. Actuators, B, 2011, 157, 329-352.

4 L. P. Martin and R. S. Glass, J. Electrochem. Soc., 2005, 152, H43-H47.

5 P. K. Sekhar, E. L. Brosha, R. Mukundan, H. Mekonen, B. Farber, C. Kreller and F. H. Garzon, Int. J. Hydrogen Energy, 2012, 37, 14707-14713.

6 M. Breedona and N. Miura, Sens. Actuators, B, 2013, 182, 40-44.

7 S. A. Anggraini, M. Breedon and N. Miura, Electrochem. Commun., 2013, 31, 133-136.

8 G. Lu, N. Miura and N. Yamazoe, Sens. Actuators, B, 1996, 3536, 130-135.

9 S. A. Anggrainia, M. Breedonb and N. Miura, Sens. Actuators, $B, 2013,187,58-64$.

10 X. Li and G. M. Kale, Sens. Actuators, B, 2007, 123, 254-261. 11 X. Li and G. M. Kale, Sens. Actuators, B, 2006, 120, 150-155. 12 X. Li and G. M. Kale, Anal. Chem., 2007, 79, 8940-8946.

13 P. K. Sekhar, E. L. Brosha, R. Mukundan, M. A. Nelson, D. Toracco and F. H. Garzon, Solid State Ionics, 2010, 181, 947-953.

14 F. H. Garzon, R. Mukundan and E. L. Brosha, Solid State Ionics, 2010, 136-137, 633-638.

15 C. O. Park, S. A. Akbar and W. Weppner, J. Mater. Sci., 2003, 38, 4639-4660.

16 T. Hibino, S. Tanimoto, S. Kakimoto and M. Sano, Electrochem. Solid-State Lett., 1999, 2, 651-653.

17 R. Moos, K. Sahner, M. Fleischer, U. Guth, N. Barsan and U. Weimar, Sensors, 2009, 9, 4323-4365.

18 R. Sun, Y. Guan, X. Cheng, Y. Guan, X. Liang, J. Ma, P. Sun, Y. Sun and G. Lu, Sens. Actuators, B, 2015, 210, 91-95.

19 P. K. Sekhar, E. L. Brosha, R. Mukundan, M. A. Nelson, T. L. Williamson and F. H. Garzon, Sens. Actuators, B, 2010, 148, 469-477.
20 Y. Guan, C. Li, X. Cheng, B. Wang, R. Sun, X. Liang, J. Zhao, H. Chen and G. Lu, Sens. Actuators, B, 2014, 198, 110-113.

21 Z. Tang, X. Li, J. Yang, J. Yu, J. Wang and Z. Tang, Sens. Actuators, B, 2014, 195, 520-525.

22 Y. Li, X. Li, Z. Tang, Z. Tang, J. Yu and J. Yang, Sens. Actuators, $B, 2015,206,176-180$.

23 Y. Li, X. Li, Z. Tang, J. Wang, J. Yu and Z. Tang, Sens. Actuators, B, 2016, 233, 365-371.

24 R. C. Weast, Handbook of physics and chemistry, CRC Press, Boca Raton, 1983.

25 V. V. Eremenko and V. M. Naumenko, JETP Lett., 1968, 7, 326-331.

26 D. L. R. Thelma, C. M. Virginia, D. V. D. Manuel and L. O. Alejandro, Int. J. Chem. React. Eng., 2007, 5, P.A30.

27 Q. Diao, F. Yang, C. Yin, J. Li, S. Yang, X. Liang and G. Lu, Solid State Ionics, 2012, 225, 328-331.

28 L. Dai, G. Yang, H. Zhou, Z. He, Y. Li and L. Wang, Sens. Actuators, B, 2016, 224, 356-363.

29 F. Sun, X. Li, L. Liu and J. Wang, Sens. Actuators, B, 2013, 184, 220-227.

30 Q. Feng, X. Li, J. Wang and A. M. Gaskov, Sens. Actuators, B, 2016, 222, 864-870.

31 X. Li, X. Li, Z. Li, J. Wang and J. Zhang, Sens. Actuators, B, 2017, 240, 273-277.

32 X. Xie, Y. Li, Z. Liu, M. Haruta and W. Shen, Nature, 2009, 458, 746-749.

33 W. Y. Li, L. N. Xu and J. Chen, Adv. Funct. Mater., 2005, 15, 851-857.

34 H. J. Kim and J. H. Lee, Sens. Actuators, B, 2014, 192, 607-627. 35 S. Vetter, S. Haffer, T. Wagner and M. Tiemann, Sens. Actuators, B, 2015, 206, 113-138.

36 J. Deng, R. Zhang, L. Wang, Z. Lou and T. Zhang, Sens. Actuators, B, 2015, 209, 449-455. 